Article

\title{
The Old Wounded: Destructive Plasticity and Intergenerational Trauma
}

\author{
Brandon D. C. Fenton
}

Philosophy Department, York University, Toronto, ON M3J 1P3, Canada; fenton.brandon@gmail.com

Received: 1 April 2018; Accepted: 18 May 2018; Published: 22 May 2018

\begin{abstract}
This article addresses a significant gap in trauma theory and philosophy; namely, it develops a partial theory of the subject of intergenerational trauma. This is accomplished through a close examination of Catherine Malabou's theory of the subject of trauma, as well as by contact with the research in epigenetics of Rachel Yehuda, and the research on intergenerational trauma among First Nations people in Canada conducted by Amy Bombay and colleagues. It presents original work that is responsive to recent advances in a variety of fields, including philosophy, psychology, social science, and biology.
\end{abstract}

Keywords: intergenerational trauma; trauma; plasticity; destructive plasticity; Malabou; Freud; epigenetics; indigenous

"As a result of serious trauma, or sometimes for no reason at all, the path splits and a new, unprecedented persona comes to live with the former person, and eventually takes up all the room. An unrecognizable persona whose present comes from no past, whose future harbors nothing to come, an absolute existential improvisation ... out of a deep cut that opens in a biography." -(Malabou 2012b)

The above quotation introduces us to the central issue of Malabou's Ontology of the Accident (OA). There, as well as in her book The New Wounded (TNW), Malabou takes on, as a project, the theorizing of the subject of trauma. It is a project that addresses a serious lack in neurological, psychoanalytical, and philosophical theory - which is not to say that these disciplines have failed entirely to consider the traumatized subject; but rather, that where they do regard the phenomenon of trauma, they tend to do so in absence of a theory of the subject of trauma, and thus, their observations and analyses remain fragmentary. The primary question that Malabou raises in these two works is the following: how do we think the traumatized subject? In both books, however, Malabou's analysis of the topic of trauma and its accompanying destructive plasticity is limited to its impact upon 'a biography.' In other words, it is most pointedly concerned with the impacts of trauma upon an individual life. ${ }^{1}$ But, the impacts of trauma rarely confine themselves solely to the individual. Instead, the legacy of trauma often cascades outward from the subject and may manifest or be felt in many different spaces; in their communities, friendships, gatherings, places of work, and family, et cetera. And, traumatic events also often traumatize more than just a single person. Indeed, the impacts of traumatic events upon entire communities and peoples are widely recognized. It would appear then, that questioning the subject of intergenerational trauma may be a more beneficial vantage point from which to understand

1 It should be noted here however, that by "individual" I do not mean to imply that the life and identity of the traumatized person thereby remains "whole" or "unbroken" for Malabou. Indeed, such a rendering would appear to deeply misunderstand Malabou's project. 
the extended effects of trauma's destructive legacy; and just as Malabou's theory of the subject of trauma (i.e., the new wounded) helps to address a lack in theory which promises to improve our understanding of these types of subjects, and how best to support and treat them, so too does a theory of the subject of intergenerational trauma aid to increase our understanding of a particular type traumatized subject, in the hopes that such knowledge will be of use in guiding us towards more helpful ways to address their needs. Therefore, in this paper, I have set myself the task of beginning to theorize the subject of intergenerational trauma or, what I am calling "the old wounded". ${ }^{2}$ This subject, while not the first to have suffered the traumatic harm ${ }^{3}$ in question, nevertheless suffers from the legacy of that trauma-the ley lines of which, as we will see, may be psychological (with impacts upon consciousness), biological (i.e., hereditary), affective, and sociocultural, or any combination of these.

I will be assisted in this task by a close companioning with Malabou's views on the subject of trauma, as well as by important contact with (among others) the pioneering work in epigenetics of Rachel Yehuda, and the comprehensive study of intergenerational trauma among First Nations peoples in Canada conducted by Amy Bombay and colleagues.

Allow me to begin with a consideration of the two most pertinent concepts for elucidating the territory before us-viz. the idea of the subject of trauma and the concept of destructive plasticity.

With respect to Malabou's characterization of the subject of trauma, we are confronted first and foremost with the image of a subject transformed-indeed, of a metamorphosis in personality so complete that the idea of a continuity between the identity of the subject prior to the trauma-be it a sort of narrative continuity or otherwise-and the identity of the subject after undergoing the trauma is radically put into question. Moreover, the subject of trauma or, the new wounded as Malabou calls them, share a particularly disconcerting set of attributes, including a more withdrawn, detached, indifferent, and emotionally cold or flat affective profile, in addition to various cognitive and emotional impairments, along with memory deficits, and radical alterations to their personalities, or even depersonalization. These are people whose closest friends and family members are inclined to say about them that they are no longer the same person, or that the person they once knew and loved is gone. The new wounded, Malabou reveals, are made up of both those who have experienced some form of physical brain trauma or degenerative disease, as well as other disturbances resulting from psychological trauma. What unifies this class of people is not the form of the injury-be it somatic or psychological-but rather, that they all suffer from "emotional disturbances that essentially consist in the malfunctioning of affective signals necessary to make decisions" and that, "to differing degrees, they all display permanent or temporary behaviours of indifference or disaffection." (Malabou 2012a). There is more to be said to flesh out a picture of who the new wounded are-and they will become more sharply outlined as they are contrasted with what I am calling the old wounded-but the above is sufficient to give a sense of their unique standing.

One further point that will make Malabou's project clearer to us, is to recognize its close relation to earlier psychoanalytic theory. She develops her thought in relation to Freud's theory in part to elaborate the "bridge between the cerebral and psychic" that is, to be found in the emotional brain-and which, according to her, "constitutes a secret economy of affects and the dark core of destructive plasticity" (Malabou 2012a). Indeed, Malabou claims that "such an economy must be articulated with and against the traditional concept of the unconscious" (Malabou 2012a). She is

2 The label "the old wounded" is a phrase that I am using to specify a particular kind of traumatic subject. Briefly, it is a subject that suffers from inherited consequences of trauma exposure that include, but are not limited to, increased vulnerabilities to things like post-traumatic stress disorder, anxiety, depression, and substance abuse disorder. In part, the label is being deployed in order to emphasize that the subject of intergenerational trauma represents a special case in traumatology that demands an adequate theoretical understanding; ultimately, in order to develop appropriate therapeutic responses (see, for example: Quinn (2007); Menzies (2010); Roy (2014)).

3 However, nothing precludes the possibility that the subject of intergenerational trauma may undergo firsthand traumatic harms of their own - the point is only that, insofar as we are considering the subject of intergenerational trauma, the trauma in question must have its origin in the experience of an earlier ancestor. 
interested in the elucidation of a theoretical subject that is multidimensional, and not reducible to the mere neurological underpinning of their lived experience. Nevertheless, she is also concerned with giving adequate regard to the body (in particular, the brain, and more recent neuroscientific discoveries about it) in ways that traditional psychoanalytic theorizing has failed to do. Indeed, she claims, "the appellation "new wounded," therefore, designates people who suffer from psychic wounds that traditional psychoanalysis cannot understand — that is to say, understand and thus consider as relevant to its jurisdiction" (Malabou 2012a). Which is not to say that Freud didn't recognize these types of traumatized subjects, certainly he did, but the neuroscience of his time simply wasn't at a stage of development whereby an understanding of the brain's affective systems could be as illuminating to psychoanalysis as they are today. And because of this, the development of her thought about the new wounded takes shape through a sometimes complimentary but often antagonistic encounter with Freud.

There are significant differences between the new wounded and those who I am referring to as the old wounded, however, and identifying these differences will help us to gain a better understanding of each as well as a fuller picture of the impacts of various forms of somatic, psychological, and cultural trauma. But first, let us consider one of the other primary concepts deployed by Malabou; namely, destructive plasticity.

As it is most frequently championed, in recent decades, the notion of plasticity is typically characterized as a sort of entirely positive phenomena, capable of solving any number of cognitive impairments by essentially redirecting neural resources in adaptive and novel ways. Indeed, Rose and Rose (2016) argue that the notion of plasticity "has become a quasi-magical term within public-policy discourse, offering an entirely new solution to problems of child development and poor educational performance, and [is being] heralded as the new elixir by the self-help manuals." According to them, the way in which the notion of plasticity is marketed outside of the technical confines of neuroscientific research, often functions to instill the false hope that people can remake themselves through their plasticity, regardless of their "embodied location in the complex intersections of the cultural, social, economic, historic and environmental" (Rose and Rose 2016). This characterization of plasticity is related to the two positive forms of the concept identified by Malabou; namely, the ability to receive and to give form. But, there is a third way in which plasticity has been and can be thought of - that is, from a more negative or negating perspective of the destruction of form. Indeed, the positive characterizations in popular sources forget the wound, and imagine injury and loss of function as merely opportunities for the creative work of constructive plasticity to dazzle us. But as Malabou recognizes and emphasizes in her work, there are some traumas and wounds against which constructive plasticity is no match, where it fails to creatively harness resources to restore what once was. But this, of course, does not mean that plasticity is not still close to the wound. Rather, it shows us the destructive side of the plastic; as Malabou (2012a) puts it:

It is clear that wounds-traumas or catastrophes-are not "creators of form" in the positive sense of the term ... If the wound, as the determining cause of the transformation of the psyche, has a plastic power, it can only be understood in terms of the third sense of plasticity: explosion or annihilation. If brain damage creates a new identity, this creation can be only creation through the destruction of form. The plasticity at stake here is thus destructive plasticity.

It is important to recognize here that, according to Malabou, although destructive plasticity may appear to bring about something new (viz. a new identity), it is not something that is creatively added to, or constructively reconfigured from what existed before. Instead, it reveals what appears as new through loss, and destruction. Its new products emerge through a sort of privation from what existed previously. Again, there is more to be said to give flesh to an understanding of destructive plasticity, but our handle on what it means and entails will continue to be shaped as the paper advances. For now, the above introduction to the concept allows us to situate the idea of destructive plasticity against the 
more mainstream positive characterizations of the phenomenon as a form of plasticity born of the wound in its destructive power, and not merely as something that aims to triumph over it.

However, as with the notion of the new wounded mentioned earlier, here again, I would like to say something about how Malabou's concept of destructive plasticity connects with the earlier Freudian understanding of the phenomenon of plasticity, as this will reveal one important difference in the way that the new wounded and the old wounded are conceived.

According to Malabou, in Freudian theory, the concept of plasticity identifies and helps to specify two primary phenomena: first, the vitality of the libido, in terms of its ability to counteract fixation and change its object; and second, "the indestructible character of psychic life" (Malabou 2012a). But it is only the second of these phenomena that interests us: the unbreakable nature of the psyche, whose imprints and traces cannot be forgotten. Indeed, in his Thoughts for the Times on War and Death, Freud claims, "What are called mental diseases, inevitably produce an impression in the layman that intellectual and mental life have been exposed to destruction. In reality, the destruction only applies to later acquisitions and developments. The essence of mental disease lies in a return to earlier states of affective life and of functioning." (Freud 1950) Although a person may experience trauma (either physical or psychological), according to Freud, the way in which this impacts the subject is, in fact, not by destroying any part of the psyche, but rather, by imposing a form of regression upon the subject-be it either in terms of a regression to an earlier child-like character or to the primitive, earlier history of the psyche's development in the species.

There are several important things to mention here. First, it must be noted, that there is a distinction to be made within the Freudian theory of trauma, and it is one that applies to the view advanced by Malabou as well. As Marcuse notes in his Eros and Civilization (Marcuse 1955), one may distinguish two levels to Freud's thought; namely, what Marcuse labels the ontogenetic (which has to do with the growth and development of the repressed individual), and the phylogenetic (which concerns the multi-generational growth and development of repressive civilization from the "primal horde" to a civilized state). In both his Thoughts for the Times on War and Death (Freud 1950) and in his introduction to Psycho-Analysis and the War Neuroses (Freud 1921), Freud appears to focus primarily upon the ontogenetic. However, in both his Totem and Taboo (Freud 1919) and especially Moses and Monotheism (Freud 1939), a phylogenetic view of the transmission of trauma is central. ${ }^{4}$ Indeed, in the latter, much of what Freud suggests would appear to anticipate recent scientific advances in the sort of epigenetic research that will be presented later on in this paper. For just one example, Freud states: "a new complication arises, however, when we become aware that there probably exists in the mental life of the individual not only what he has experienced himself, but also what he brought with him at birth, fragments of phylogenetic origin, an archaic heritage." (Freud 1939) This sort of phylogenetic understanding of trauma may be contrasted with the more ontogenetic view developed by Malabou in her OA and TNW, given that these two works focus on personal metamorphosis; however, Malabou has also very recently written on trauma inheritance and its epigenetic character. ${ }^{5}$ So, both Freud and Malabou have examined and advanced accounts of both the ontogenetic and phylogenetic aspects of trauma. However, unlike the ontogenetic perspective used by Malabou in OA and TNW to characterize the new wounded, in this paper, I will develop a primarily phylogenetic view of trauma in order to advance an understanding of the old wounded.

Next, I want to draw our attention to the fact that, in order for Freud to be able to psychoanalytically theorize trauma-due to the limited state of brain science at the time of his writing - he would have had to insist on the integrity of the psyche despite injury; and so it follows that, in order to register the apparent cognitive and affective deficits observed in traumatized patients, his only theoretical option would appear to be to characterize their conditions in terms of a regression;

4 Here I must say thank you to one of the reviewers of this paper for reminding me of the importance of Freud's later work to the view being developed in this paper.

5 See Malabou (2018) Is Psychic Phylogenesis Only a Phantasy? New Biological Developments in Trauma Inheritance. 
since, this seems to accommodate both the obvious impairments to functioning and yet still preserves an idea of the psyche that is amenable to psychoanalysis as a useful therapeutic practice. It should also be noted, however, that Malabou marshals the recent empirical evidence of the neurosciences to challenge Freud here. For her, the concept of destructive plasticity remains a more suitable means for thinking through the sorts of full-fledged metamorphosis that are often witnessed in the appearance of the new wounded.

Interestingly, the understanding of the old wounded that I will be presenting appears to draw, in part, upon both the Freudian view, as well as the view developed by Malabou. In short, the old wounded, as I understand them, carry a trace similar to that indestructible psychic element identified by Freud, while at the same time, this trace is partially rooted in a loss that is an outcome of a somatic (and psychological) destruction. But, this similarity to aspects of the theories of both Freud and Malabou masks a difference between our understandings as well: whereas Freud sought to preserve the integrity of the psyche of the traumatized subject, I recognize that for the old wounded, there is a sense in which psychic integrity is corrupted; and whereas Malabou saw the new wounded as often displaying a total metamorphosis of personality, I recognize in the old wounded not a change brought about through metamorphosis, but rather, a loss that precedes their existence-made manifest through a sort of destructive plasticity that is only revealed through the vulnerabilities acquired by inherited wounds, the sources of which were not directly suffered; but more on this later.

At one point, in TNW, Malabou claims that her work in this area represents both a return to the past and an emergent phenomenon-saying of the new wounded that they are also the old wounded, because the types of psychological disorders or impairments that they present had long been identified-indeed, she acknowledges that "Freud the neurologist knew them on sight" (Malabou 2012a). However, she argues that, "at the same time, these pathologies are "new" to the extent that we are beginning today to appreciate not only their organic but also their psychic effects" and this points to what she sees as a new phenomenon, which is that, "from now on, people with brain lesions [or trauma] will form an integral part of the psycho-pathological landscape" (Malabou 2012a). While I agree with Malabou on this point, and would add that subjects of intergenerational trauma ought also to form an integral part of such a landscape, I must also pause here for a moment to disambiguate the understanding of the old wounded that I am developing from the way in which Malabou uses the term in passing. Whereas Malabou characterizes the kind of trauma that she is theorizing to be "old" in the sense that it had long since been recognized, and yet "new", because it is only recently that it became more thoroughly theorizable, thanks to advances in the neurosciences, my use of the phrase "the old wounded," on the other hand, is being used to identify a particular type of traumatized subject-indeed, a form of secondary traumatization residing within the offspring of those initially traumatized by some event. However, my work in theorizing these subjects is also "new" in the sense used by Malabou, given that it makes use of recent advances in epigenetic research; and at the same time, it is also "old" in Malabou's sense, because it too was long ago recognized by Freud, and an awareness of this phenomenon has also long been known to First Nations peoples by way of the concepts of "blood memory" and "soul wound". 6

Allow me, for a moment, to use a common metaphor in order to help to illustrate the most salient difference between Malabou's new wounded and the old wounded that I am speaking of. The impacts of psychological trauma have often been related to the falling of a pebble into calm pond. The pebble disturbs the surface of the water long after the initial moment of impact between them; and the ripples upon the surface spread out in all directions. The lastingness of the disturbance is often used to illustrate the enduring nature of the harm wrought by the traumatic event-a lastingness, that in the case of Malabou's new wounded, may only come to an end when they do. And, the ripples spreading out in all directions are often used to express the wide range of the impacts that the trauma may

6 See for example: Duran (2006). 
produce; as mentioned earlier, these can include impacts in communities, friendships, gatherings, places of work, and family, et cetera. These distributed impacts from trauma are true of both the new and the old wounded. However, what is often left out of such a metaphor is the fact that even though the surface of the pond may eventually return to stillness, the pond itself remains forever changed by the impact of the pebble-and not just because that event is a part of the pond's history, but also because somewhere, in the depths of the pond, that pebble remains lodged, altering the shape and level of the water in ways that are not necessarily easily noticed on the surface. It is this deep, enduring impact of the trauma, as it spans across generations, that concerns an understanding of the old wounded. There is the obvious way in which this treatment of the metaphor reveals the lasting impacts of the trauma from one generation to the next, beyond the initial ripples of the disturbance, but it also evokes a sense of the depths, which are often depicted as the realm of the unconscious. And, there is something to be said about the ways in which the intergenerational transmission of the impacts of trauma are often unconscious as well — but more will be said about this point later.

Next, I will turn to what is "new" about the old wounded-namely, that there is now empirical evidence which supports an understanding of the biological transmission of the impacts of trauma. The primary mechanism by which such a transmission has recently been empirically investigated has to do with what are known as epigenetic factors. While genes are known to be involved in the hereditary passing on of observable physical traits from parents to their offspring, epigenetic mechanisms influence gene expression-essentially turning a gene on or off-and they can be influenced by the internal and external environment. As such, they are a type of biological mechanism of transgenerational inheritance that is sensitive, or receptive to, the environmental impacts that a person may undergo in the course of their lifespan; that is, to things like trauma. In other words, the impacts registered in a person's epigenetic profile (which includes alterations in epigenetic factors like hormone levels), due to events like undergoing traumatic experiences, may not only impact the operation of their own genes, but these gene expression-influencing factors may also be passed on to their offspring-rendering them more susceptible to suffering similar responses to these types of environmental impacts.

Turning now to the empirical research, it has been shown that the link between trauma in parents-more specifically, post-traumatic stress disorder (PTSD) — and increased rates of the same in offspring, was first identified by a group of researchers led by Solomon et al. (1988). They found that war veterans who were offspring of Holocaust survivors displayed higher rates of PTSD than did Lebanon war veterans whose parents did not directly endure the horrors of the Holocaust. And, this research was replicated and strengthened by another group of researchers led by Yehuda et al. (1998a, 1998b), who found that not only was a diagnosis of PTSD following the experience of a trauma more common in offspring of Holocaust survivors than in a similar control group where the subjects were not the offspring of Holocaust survivors, but that such a diagnosis was specifically related to parental PTSD. Since this early work on the intergenerational transmission of trauma, Yehuda has been at the forefront of much of the research done on this issue, and with a constant eye for theoretical refinement and greater specificity. In a 2008 summary of the research in this area, Yehuda identified a common thread of significantly lower levels of cortisol (a corticosteroid hormone, and epigenetic substance) among both Holocaust survivors with PTSD and in their offspring with PTSD (Yehuda and Bierer 2008). Moreover, their research found that, in all of the studies examined, the severity of parental PTSD was negatively correlated with neuroendocrine measures in offspring; which means that the more severe the form of PTSD expressed by the parents, the lower the levels of things like

7 It should be mentioned here that in her treatment of the new wounded, Malabou is also very much concerned with the unconscious and she elaborates an important new understanding of what she refers to as the cerebral unconscious as it relates to another concept that is central to her work; namely, the concept of cerebrality. However, I do not have sufficient space here to enter into a full treatment of that concept. For further information on the role played by cerebrality in her work, see her: The New Wounded (Malabou (2012a)). 
cortisol in offspring. These findings have led Yehuda and others to examine the evidence that might support there being epigenetically inherited pre-traumatic risk factors that may play a role in or even predict the likelihood of the development of PTSD in the wake of a traumatic experience.

There have been several other proposals and studies seeking to identify risk factors for the onset of PTSD that have found things like personality, behaviors, and psychological traits to contribute to whether or not a person may be diagnosed with PTSD following a traumatic event (McFarlane 1989; Breslau et al. 1998). Other preceding risk factors included prior exposure to adversity (Bremner et al. 1993) or psychiatric disorder as part one's family history (McFarlane 1988; Davidson et al. 1998). There exist, therefore, a number of different potential risk factors for the development of PTSD. However, recent community-based studies have shown that participants diagnosed with PTSD were, on average, three times more likely to report a family history of mental illness composed of things like anxiety, depression, psychosis, and antisocial behavior. This general finding has been shown through studies of PTSD following combat exposure (Reich et al. 1996), rape (Davidson et al. 1998), and disaster (McFarlane 1988), which supports a heritability component to the diagnosis. Another study led by Yehuda in 2005 helped to separate the epigenetic influence upon offspring from other potentially influencing factors that may develop over the course of offspring development. In this study, cortisol levels were measured in mothers with PTSD that was brought on while pregnant by having been directly exposed to the World Trade Centre collapse on 9/11. In this case again, both the mothers with PTSD and their newborn infants had significantly lower levels of salivary cortisol than newborns and their mothers who had not developed PTSD. This would seem to rule out the possibility that the infants own trauma history might be implicated in the results. However, early attachment issues or social regulation may have played a role. Nevertheless, the cumulative impact of the abovementioned studies and others supports the case that epigenetic factors are implicated in the transmission of the impacts of traumatic stresses (viz. PTSD), from traumatized parents to their offspring.

As mentioned earlier, although the elucidation of an epigenetic biological mechanism's role in the intergenerational transmission of traumatic impacts is a fairly recent development, the presence of such a phenomenon has long been known to First Nations peoples under the names of "blood memory" and "soul wound". And, there are many important factors that may be implicated in how this phenomenon may be uniquely manifest among First Nations peoples.

Amy Bombay is Anishinaabe kwe (from Rainy River First Nation), and is a researcher in the department of Psychiatry and the School of Nursing at Dalhousie University. In 2009, Bombay and colleagues published a seminal article titled "Intergenerational Trauma: Convergence of Multiple Processes among First Nations peoples in Canada." The article identified a host of the traumatic and damaging impacts of colonization on First Nations peoples and their offspring-as well as a host of ongoing harms that remain the legacy of colonization. They identify numerous stressful events specific to the experiences of First Nations peoples and their impacts upon things like wellbeing, coping methods, parenting styles, and behavioral disturbances, among others.

With respect to some of the behavioral disturbances that often follow in the wake of traumatic stressors, they consider things like depression, anxiety, PTSD, and substance abuse disorder. The impact of these factors, along with persistent sociocultural disadvantages, the authors argue, "have acted to increase vulnerability to the transmission and expression of intergenerational trauma effects" (Bombay et al. 2009) among First Nations peoples. This work goes well beyond the narrowly biological factors-although it includes them - that are related to the intergenerational transmission of the effects of trauma. Indeed, they recognize that some of the impacts of intergenerational trauma may evade the easily observable or easily measurable given, for example, that some impacts can be related to survivors telling and retelling their stories of trauma to their offspring; and, as is widely known in traumatology, when it comes to vicarious trauma, repeatedly encountering traumatic stories in the lives of others-even those not connected to us as family - can often lead to various forms of maladaptive coping strategies, as well as the phenomenon of vicarious trauma (e.g.,: Van Dernoot Lipsky 2009). According to the authors, other difficult to quantify aspects of the harms of colonialism's 
legacy include the, "... potential effects on mental health of First Nations ... [of things like] loss of culture and languages, loss of identity, including pride and a sense of kinship with other First Nations peoples ... [which are] consequences [that] occur at the individual, family and community levels, all of which are connected and interrelated" (Bombay et al. 2009). In other words, this project identifies both the ontogenetic as well as the phylogenetic factors, and recognizes their interconnectedness when it comes to understanding the vast impacts of intergenerational trauma.

Bombay and colleagues also argue that early life trauma and other prior stressful events may increase vulnerability to pathology. They note the differences between acute stressors (which are typically of a short duration) and the sorts of ongoing stressors represented by things like racism, oppression, and chronic poverty, and the particularly dangerous combination of the two types of stressors for mental health. Moreover, they recognize that, "cultural factors likely influence the stress process and may have profound effects on how individuals cope with shared trauma" (Bombay et al. 2009) despite the fact that standard stress evaluation models often fail to account for potential cultural variables in terms of how people may appraise a stressful event, the kinds of coping strategies which they may access, and how their responses are expressed. Indeed, in their assessment of some of the historical and contemporary forms of trauma endured by First Nations peoples, Bombay and colleagues recognize that it is not just the impacts of large scale or cataclysmic events, but also the daily burden of "the lack of control over their own lives, the unpredictability of events, as well as numerous other psychosocial factors that influenced the way First Nations individuals might have appraised their situation and subsequently coped with ongoing stressors" (Bombay et al. 2009). In addition to this backdrop of persistent stresses, Indigenous people are also likely to have experienced multiple and overlapping cataclysmic traumas, starting historically with settler missionaries attempting to force religious conversion, as well as war and community massacres, followed by the creation of, and segregation onto reserve lands, the state's broken treaty promises, attempts at forced assimilation, and the outlawing of cultural ceremonies, to the more recent state-mandated Residential Schools, and forced adoption programs that tore indigenous families apart. Indeed, the history of traumatic events experienced by the Indigenous peoples of Canada is legion, and it is a history of systematic and state led ethnic and cultural genocide. ${ }^{8}$

Despite having undergone the multiple extreme traumas mentioned above, Bombay and colleagues are absolutely correct in acknowledging that, "First Nations peoples have demonstrated enormous resilience" (Bombay et al. 2009). Nevertheless, they argue, the cumulative effects of such stressors and overlapping traumas is demonstrated in "the consistent health and socioeconomic disparities that exist between First Nations and Non-Aboriginal peoples in North America" (Bombay et al. 2009). Moreover, the authors identify a major oversight of much of the research related to intergenerational trauma-that is, most of it focuses upon the experiences of the traumatized individuals or only these people and their offspring. However, there are dimensions to collectively experienced large scale traumas that produce changes in the more broadly framed social dynamics, structures, and functioning as well. They mention, for instance, that, "community level changes in the aftermath of mass trauma have included erosion of basic trust, silence, deterioration in social norms, morals and values, and poor leadership" (Bombay et al. 2009). And, such collectively experienced traumas may manifest in ways that are not obvious to those outside of a given cultural group. For instance, Bombay et al., reference Palinkas et al. (1993) when they explain that following the Exxon Valdez oil spill, Indigenous Aleuts (i.e., the Indigenous peoples of the Aleutian Islands and western Alaska made up of the Unangas and the Sugpiaq peoples) were disproportionately impacted, presenting with double the incidents of PTSD and generalized anxiety disorder than non-Indigenous residents. They also claim that " ... the natural resources destroyed by the oil spill did not simply reflect a financial loss, but undermined the Aleut identity, social organization

8 See for example: Menzies $(2006,2010)$. 
and ideology, and actually disturbed the symbols fundamental to native culture being transmitted across generations" (Bombay et al. 2009). And, this highlights another important insight of their work; namely, the recognition that the current dominant trauma literature fails to examine or account for how historical traumas interact with present-day traumas.

The pioneering works of Bombay, Yehuda, and their colleagues, sets a new standard for research in intergenerational trauma. Yehuda and her collaborators work on the biological mechanisms of the intergenerational transfer of trauma; and the work of Bombay and her collaborators on the unique cultural experiences of the horrors of colonization and intergenerational trauma among First Nations peoples in Canada are both of inestimable value to the study of trauma and human experience, generally. It is with great reverence for their work that the current project came into existence. Indeed, the subject of intergenerational trauma (or the old wounded) that I am talking about here is deeply informed and shaped by their recent research. It is a theory about what is central to a specific type of subject that may, nevertheless, display certain cultural differences.

Keeping in mind these important contributions to the research literature, I will now return to further elucidating the subject of intergenerational trauma or, the old wounded, as I am calling them. As I mentioned earlier, I maintain that the old wounded carry a trace similar to the sort of indestructible element identified by Freud, while at the same time, I conceive of this "trace" in terms of Malabou's destructive plasticity. Allow me to take a moment to clarify what I mean by this. The similarity between the Freudian view of the indestructible trace and the trace that I identify as persisting across generations lies in the aspect of the trace as something that cannot be, or in any case, has not been destroyed. For Freud, of course, the trace represents the preservation of a positive condition of the psyche-namely, that the psyche continues to exist, and that it cannot be obliterated. However, the sort of trace that I am positing with respect to the old wounded, is a negative trace; a trace borne of the sort of destruction identified by Malabou. As such, the trace of trauma that I see as being passed on to the old wounded is a trace in the negative, a trace of absence. How can destruction itself be destroyed? It is a trace that makes itself felt not as something positive, not as some vital, augmenting, creative force, nor as the integral psyche that remains ever amenable to psychoanalysis. Instead, it shares an affinity with the sort of destructive plasticity posited by Malabou. It removes form, and is form made manifest by a kind of destruction. However, its consequences are not as thoroughly metamorphic as those expressed by Malabou's new wounded. Instead, it is a type of trace that erases the event of the trauma at the same time as it inscribes and preserves it. The old wounded are not directly acquainted with the trauma of their ancestors that now, in a way, resides within them. They are subject to a strange transitivity.

The common understanding of the relation of transitivity in logic and mathematics is typically characterized in the following terms: if $a$ is equal to $b$, and $b$ is equal to $c$, then $a$ is equal to $c$. But if $a$ represents a parent who has undergone and bears the psychological and somatic scars of a traumatic event, and $b$ and $c$ represent their child and grandchild, respectively, clearly, in the case of intergenerational trauma, the relation is not one of being equal to. Nor is the relation one of mere similarity, or similarity between their collective possession of a particular property; since, for one thing, what is passed on is a negative property (a property of absence), and there are differences between how that negative property-or trace of an absence-abides within each of the subjects who make up the chain. This is what I mean when I say that the old wounded are subject to a "strange transitivity". The person to have undergone the originally traumatic event has a first-hand experience of it; the trauma makes its mark, but it also remains a consequence of something personally lived through - here, there is a direct psychological contact with the traumatic event. On the other hand, for their offspring (i.e., the old wounded), this direct familiarity with the traumatic event is missing. Nevertheless, the impacts of that ancestral trauma remain-primarily as kinds of increased psychological vulnerabilities or tendencies that would otherwise not be part of their original makeup. And, the transmission of the negative trace to the old wounded occurs at an unconscious level. They may come to know of its presence (absence as presence), to witness its impact upon their lives, 
but there is nothing voluntarily or consciously chosen about how it manifests and shapes their lives. It is the uninvited guest visited upon the unsuspecting host.

The destructive plasticity behind this strange transitivity conceals itself, erases its own movement. As such, it corrupts the personal integrity of the psyche, and stands as a challenge to the Freudian view that seeks to preserve this integrity in the face of trauma. However, this is not to say that the old wounded are therefore outside of the scope of psychoanalysis or other psychotherapeutic approaches. Instead, it is only that the negative trace which they embody becomes a significant challenge for psychoanalysis and psychotherapy, because the psychological damage or distress visited upon the old wounded by this transmitted trace of destructive plasticity is not born of the personal psyches of those afflicted-though, it is nevertheless borne by them. In other words, the origin of the vulnerabilities of the old wounded is not to be found in, for example, the ego or libidinal conflicts of the personal psyche. Instead, the existence of the old wounded demands a more nuanced approach to psychoanalysis-and, to our conception of the psyche in general. Indeed, the old wounded reveal that a conception of the psyche as strictly bound by the flesh of one body is inadequate to the task of making sense of the reach of trauma's impacts. The old wounded are wounded before their time, arrive on the scene already embodying an absence-the remnant damage of a blow not personally sustained. Moreover, as Freud suggests, they "can only be understood phylogenetically, in relation to the experiences of earlier generations" (Freud 1939).

I mentioned at the outset that this paper represents only a beginning to the larger project of theorizing the old wounded, and although I have situated my analysis within, and as responsive to the larger research on the topic, there remains much more work yet to be done; work that I hope to be able to contribute further to, in the near future. However, I would be remiss if I did not use the remaining space I have to say something about avenues of healing for the old wounded, as well as the relevance of this work to the practice of law.

How does one begin to heal the wounds that one carries, and yet, has not incurred through any action or direct experience of one's own? How do the generations of traumatized subjects begin the process of healing? How do entire communities and cultures impacted by trauma respond to their wounds and wounded? Are individualized western therapeutic models up to the task? To the last question, it might be said that any psychotherapeutic approach that does not address the cultural and intergenerational impacts of trauma could never achieve completeness; could not address the entire scope of the wound. But, with respect to the other questions, we may turn to witness how communities have responded to these wounds for themselves. Indeed, where entire peoples have been traumatized by vast acts of aggression and oppression, they have not, in general, waited on the psychoanalysts or psychotherapists to save them. Instead, communities that have undergone such horrors have frequently turned to each other for support, care, and to rebuild the internal bonds, and reclaim what was taken from them. When entire communities are harmed, entire communities tend to come together to heal. This often takes the form of cultural or spiritual ceremony and social practices. Indeed, actively coming together in these kinds of ways, as Bombay notes with respect to Indigenous communities, "can encourage resilience in the face of traumatic stresses" (Bombay et al. 2009). And, this may be because it provides the space for a recognition that, despite the horrors that may have been imposed upon them, they remain; and more than that, they remember, and they resist, together. Again, there is much more that could be said about how community or collective responses to trauma may act to support not just the healing of the social and cultural dynamics of those communities and collectives, but also support the healing of those individuals that are a part of them. But for now, I would like to say a few things about the potential impacts of intergenerational trauma in the law.

The Canadian Government has recently been engaged in attempting to address some of the undeniable harms it is responsible for inflicting upon Indigenous peoples through colonization and its ongoing legacy. These efforts have taken various forms, from, for example, the recent Truth and Reconciliation Commission, and the Indian Residential Schools Settlement Agreement (IRSSA). The IRSSA, announced in 2006, was the largest class action settlement in Canadian history. 
It established a $\$ 2$ billion dollar compensation package for all former Residential School attendants. But, with trauma's legacy having an intergenerational component, the case could be made that the reparations and compensation packages for historical harms ought to not only compensate those who were directly impacted by things like the forced attendance at Residential Schools, but also their offspring; many of whom suffered not only as the old wounded, but also as a result of the widespread damage to the parenting efficacy and care of parents who were torn away from their own parents at a young age and conditioned primarily through violent, culturally destructive, and abusive social dynamics. Indeed, as Menzies (2010) notes: "Canadian social policy has been instrumental in creating institutions that have attempted to eradicate Aboriginal worldview and value systems that existed for thousands of years, replacing them with doctrines that continue to disrupt life for Aboriginal peoples." Therefore, greater acknowledgment of the ongoing legacies of these harms could aid in the development of informed and helpful social programing and projects aimed at empowering communities to institute more of their own culturally appropriate forms of community responses. As mentioned, there is much work left to be done on many of the topics central to this paper, but with greater visibility and recognition, we may develop a fuller understanding of the old wounded and uncover better ways to support them in their healing journeys, as well as better ways to respond to the historical wrongs that often form a potent part of their deeply interconnected personal, familial, and social lives.

Conflicts of Interest: The author declares no conflict of interest.

\section{References}

Bombay, Amy, Kim Matheson, and Hymie Anisman. 2009. Intergenerational Trauma: Convergence of Multiple Processes among First Nations peoples in Canada. Journal of Aboriginal Health 5: 6-47.

Bremner, J. Douglas, Steven M. Southwick, David R. Johnson, Rachel Yehuda, and Dennis S. Charney. 1993. Childhood physical abuse and combat-related posttraumatic stress disorder in Vietnam veterans. The American Journal of Psychiatry 150: 235-39. [PubMed]

Breslau, Naomi, Ronald C. Kessler, Howard D. Chilcoat, Lonni R. Schultz, Glenn C. Davis, and Patricia Andreski. 1998. Trauma and post-traumatic stress disorder in the community: The 1996 Detroit Area Survey of Trauma. Archives of General Psychiatry 55: 626-32. [CrossRef] [PubMed]

Davidson, Jonathan R. T., L. A. Tupler, W. H. Wilson, and K. M. Connor. 1998. A family study of chronic post-traumatic stress disorder following rape trauma. Journal of Psychiatric Research 32: 301-9. [CrossRef]

Duran, Eduardo. 2006. Healing the Soul Wound: Counseling with American Indians and Other Native Peoples. New York: Teachers College Press.

Freud, Sigmund. 1950. Thoughts for the Times on War and Death. In The Standard Edition of the Complete Psychological Works of Sigmund Freud. Translated by James Strachey. London: Hogarth Press. First published 1915.

Freud, Sigmund. 1919. Totem and Taboo. New York: Moffat, Yard and Company.

Freud, Sigmund. 1921. Introduction to S. Ferenczi, K Abraham, E. Simmel \& E. Jones'. In Psycho-Analysis and the War Neuroses. New York: The International Psycho-Analytical Press.

Freud, Sigmund. 1939. Moses and Monotheism. New York: Vintage Books.

Malabou, Catherine. 2012a. The New Wounded: From Neurosis to Brain Damage. New York: Fordham University Press.

Malabou, Catherine. 2012b. Ontology of the Accident: An Essay on Destructive Plasticity. Cambridge: Polity Press.

Malabou, Catherine. 2018. Is Psychic Phylogenesis Only a Phantasy? New Biological Developments in Trauma Inheritance. In Freud and Monotheism: Moses and the Violent Origins of Religion. Edited by Gilad Sharvit and Karen S. Feldman. New York: Fordham University Press, pp. 177-98.

Marcuse, Herbert. 1955. Eros and Civilization: A Philosophical Inquiry into Freud. New York: Vintage Books.

McFarlane, Alexander Cowell. 1988. The aetiology of post-traumatic stress disorders following a natural disaster. British Journal of Psychiatry 152: 116-21. [CrossRef] [PubMed]

McFarlane, Alexander Cowell. 1989. The aetiology of post-traumatic morbidity: Predisposing, precipitating and perpetuating factors. British Journal of Psychiatry 154: 221-28. [CrossRef] [PubMed] 
Menzies, Peter. 2006. Intergenerational Trauma and Homeless Aboriginal Men. Canadian Review of Social Policy 58: $1-24$.

Menzies, Peter. 2010. Intergenerational Trauma from a Mental Health Perspective. Native Social Work Journal 7: 63-85.

Palinkas, Lawrence A., Michael A. Downs, John S. Petterson, and John Russell. 1993. Social, cultural, and psychological impacts of the Exxon Valdez oil spill. Human Organization 52: 1-13. [CrossRef]

Quinn, Ashley. 2007. Reflections on Intergenerational Trauma: Healing as a Critical Intervention. First Peoples Child \& Family Review 3: 72-82.

Reich, James, M. Lyons, and B. Cai. 1996. Familial vulnerability factors to post-traumatic stress disorder in male military veterans. Acta Psychiatrica Scandanavica 93: 105-12. [CrossRef]

Rose, Hilary, and Steven Rose. 2016. Can neuroscience change our minds? Cambridge: Polity Press.

Roy, Amrita. 2014. Intergenerational Trauma and Aboriginal Women: Implications for Mental Health during Pregnancy. First Peoples Child \& Family Review 9: 7-21.

Solomon, Zahava, Mario Mikulincer, and Ehud Avitzur. 1988. Coping, locus of control, social support, and combat-related post-traumatic stress disorder: A prospective study. Journal of Personality and Social Psychology 55: 279-85. [CrossRef] [PubMed]

Van Dernoot Lipsky, Laura. 2009. Trauma Stewardship: An Everyday Guide to Caring for Self While Caring for Others. Oakland: Berrett-Koehler.

Yehuda, Rachel, and Linda M. Bierer. 2008. Transgenerational transmission of cortisol and PTSD risk. Progress in Brain Research 167: 121-35. [PubMed]

Yehuda, Rachel, James Schmeidler, Earl L. Giller Jr., Larry J. Siever, and Karen Binder-Brynes. 1998a. Relationship between posttraumatic stress disorder characteristics of Holocaust survivors and their adult offspring. American Journal of Psychiatry 155: 841-43. [CrossRef] [PubMed]

Yehuda, Rachel, James Schmeidler, Milton Wainberg, Karen Binder-Brynes, and Tamar Duvdevani. 1998b. Vulnerability to posttraumatic stress disorder in adult offspring of Holocaust survivors. American Journal of Psychiatry 155: 1163-71. [CrossRef] [PubMed]

(C) 2018 by the author. Licensee MDPI, Basel, Switzerland. This article is an open access article distributed under the terms and conditions of the Creative Commons Attribution (CC BY) license (http:/ / creativecommons.org/licenses/by/4.0/). 